\title{
THE IMPACT OF RESISTANCE TRAINING VOLUME ON MUSCLE SIZE AND LEAN BODY MASS: TO INFINITY AND BEYOND?
}

review paper

( ) University School of Physical Education in Wroclaw

DOI: https://doi.org/10.5114/hm.2020.94199

\section{DANIEL SOUZA, MATHEUS BARBALHO, PAULO GENTIL}

Faculty of Physical Education and Dance, Federal University of Goiás, Goiânia, Brazil

\begin{abstract}
Purpose. To conduct a narrative review of relevant studies comparing the impact of different resistance training (RT) volumes on muscle hypertrophy and lean body mass.

Methods. Studies were eligible for inclusion if they were clinical trials comparing the effects of different RT volumes on muscle hypertrophy and body composition. Overall, 22 articles were considered relevant and included in this review after an extensive literature hand search of the following databases: SciELO, PubMed/MEDLINE, Scopus, SPORTDiscus, LILACS, and Web of Science.

Results. Of the 22 studies, 6 showed greater effects of high-volume, 1 showed greater effects of low-volume, and the remaining studies showed no difference between high- and low-volume RT. Five studies that revealed better results for higher volume were performed in untrained people, 1 concerned trained people, and the study that presented better results for lower volume referred to trained subjects. High heterogeneity was observed in the studies' methodology regarding training protocols, population characteristics, length of intervention, supervision status, and measures of muscle size and body composition. Conclusions. Our findings suggest that muscle size and lean body mass are not mainly affected by RT volume and that other variables, especially the intensity of effort, should be considered in RT prescription. In this sense, increased volume could be beneficial, especially when training with low effort or when effort is not well controlled. However, it is important to note that there seems to be a ceiling effect and the use of higher volumes might be detrimental to muscle hypertrophy over a long term.
\end{abstract}

Key words: strength training, muscle hypertrophy, intensity, fat free mass, body composition, bodybuilding

\section{Introduction}

Skeletal muscle tissue plays an important role in metabolic health and functionality, as well as in life expectancy in both women and men [1-3]. Considering the age-related muscle loss, the increase or maintenance of lean mass are desirable to prevent health declines throughout life [4-6]. Moreover, increases in muscle size are commonly pursued with aesthetic or competitive purposes, like in bodybuilding. Resistance training (RT) is considered one of the most effective exercise-based strategies to promote muscle hypertrophy and increases in lean body mass [7, 8]. The achievement of optimum results from RT seems to be dependent on the manipulation and combination of several variables involved in its prescription (e.g. exercise selection, frequency, intensity, time under tension, supervision) $[9,10]$. One of them is RT volume, which is related to the 'quantitative' aspect of training and may be described as the product of load $\times$ sets $\times$ repetitions (i.e. volume load) or just the number of sets (i.e. volume set).

Previous systematic reviews with meta-analyses suggested that increases in muscle mass occurred in a dose-response manner in relation to the number of sets [11, 12]. On this basis, it might be argued that muscle adaptations are mainly affected by the volume of training, following the adage 'the more, the better'. However, these findings favouring a 'volume-based theory' should be interpreted carefully, since metaanalyses involving RT research do not consider the large inconsistencies among research methods and the complexity involved in RT prescription [9, 13, 14]. Moreover,

Correspondence address: Paulo Gentil, Faculdade de Educação Física e Dança, Universidade Federal de Goiás, Avenida Esperança s/n, Campus Samambaia - CEP: 74.690-900, Goiânia - Goiás - Brasil, e-mail: paulogentil@hotmail.com

Received: December 9, 2019

Accepted for publication: March 3, 2020

Citation: Souza D, Barbalho M, Gentil P. The impact of resistance training volume on muscle size and lean body mass: to infinity and beyond?. Hum Mov. 2020;21(4):18-29; doi: https://doi.org/10.5114/hm.2020.94199. 
systematic reviews with meta-analyses on the topic have not provided subgroup analysis, which makes it difficult to identify potential dissimilar results regarding participants or training characteristics (e.g. trained or untrained).

As an alternative, other authors have proposed that muscle adaptations are triggered when a stimulatory threshold is surpassed and the results increase until an upper limit; after this, an increase in training volume might not provide further benefits [15-19]. One example for this theory has been shown in protein syntheses response to RT in an animal model [20]. Considering this 'threshold theory' and the wide possibility of $\mathrm{RT}$ variables to combine, it is reasonable to suggest that the stimulatory threshold could be surpassed in different ways. Another important variable that should be considered in RT prescription is the intensity of effort $[21,22]$, which is related to the proximity of momentary muscle failure [23, 24] Whilst it has been discussed for beginners [25-27], the performance of sets until momentary muscle failure seems important to increase adaptations in experienced resistance-trained individuals [28] Further, RT involving higher intensity of effort seems to induce greater positive changes in metabolic function and, subsequently, body composition improvements [29]. In this context, the intensity of effort emerges as an important variable to consider, as the optimal volume or the upper volume threshold might decrease with increased training intensity [18].

The conflicting results regarding the effects of RT volume on muscle adaptations might be influenced by study heterogeneity and the complexity involved in RT prescription, which makes it difficult to draw general conclusions from meta-analysis studies [9, 13]. Therefore, the purpose of the present study was to provide a critical narrative review of relevant studies comparing different RT volumes as an attempt to better understand the factors that might explain the conflicting results involving the relation between muscle hypertrophy, increases in lean body mass, and training volume, here defined as the number of sets.

\section{Literature search methodology}

We opted for a narrative because it is generally more comprehensive and able to cover a wider range of issues. However, in order to minimize the problems inherent to it, we detailed the methods used in our search, and critically appraised and synthesized the available literature.

The narrative review was conducted after an extensive literature search of the following databases:
SciELO, PubMed/MEDLINE, Scopus, SPORTDiscus, LILACS, and Web of Science. All considered relevant papers that examined the effects of RT volume on muscle hypertrophy were included in this review. In the search process, the following keywords were used: 'volume,' 'total training volume, ' 1 set,' ' 3 sets,' 'single set,' 'multiple set,' 'dose-response,' and their respective abbreviations and combinations, in addition to 'hypertrophy,' 'muscle mass,' 'muscle size,' 'lean body mass'. The literature research involved an emergent approach as the search progressed, including searching references of references and using personal contact with authors and colleagues knowledgeable in the area. Similarly, manual research was conducted in specific strength and conditioning journals and lists of references obtained from articles. This process resulted in the inclusion of 23 original articles addressing RT volume as the main variable. The last survey was performed on November 15, 2019. In the end, only studies comparing the effects of different training volumes on an independent variable that was muscle hypertrophy were included. The review included articles in English. Studies were excluded if they were only reviews or abstracts, if clinical populations or people with joint or musculoskeletal problems were involved, or if the intervention of RT was confused by other factors, such as other forms of exercise, diet, or pharmacological intervention. Lean body mass was also included in the analysis because skeletal muscle is its major component modifiable in response to an exercise intervention.

The classification of the participants' training status (i.e. trained or untrained) was in accordance with the description obtained in the original papers. The weekly volume set performed per muscle group was considered as an objective and practical measure of volume.

\section{Ethical approval}

The conducted research is not related to either human or animal use.

\section{Volume of set, muscle hypertrophy, and body composition}

\section{Untrained subjects}

We found 14 studies investigating the effects of RT volume on muscle hypertrophy in untrained subjects. The characteristics of the studies are described in Table 1. Starkey et al. [30] investigated the effect of 3 vs. 9 weekly sets per muscle group on muscle hypertrophy in untrained subjects of both sexes. The partici- 
D. Souza, M. Barbalho, P. Gentil, Resistance training volume, muscle size, and lean body mass

pants performed bilateral knee extension alternated with knee flexion until volitional fatigue. The intensity of effort was assessed by rating of perceived effort (RPE), with participants achieving maximum values at the end of experiment. Both groups obtained significant increases in thigh muscle hypertrophy after the 14-week training period, with no significant difference between conditions. McBride et al. [31] compared the effects of 2 vs. 12 weekly sets per muscle group on body composition in untrained subjects. The participants performed biceps curl, leg press, chest fly, abdominal sit-ups, and back extension following an undulating periodization. Neither RT volume provided significant increases in lean body mass.

Galvão and Taaffe [32] investigated the effects of 2 vs. 6 weekly sets per muscle group in older women. The participants performed full-body routines involving chest press, seated row, triceps extension, biceps curl, leg press, leg curl, and leg extension exercises. The sets were performed until momentary muscle failure. There were no differences in changes in lean body mass between RT volumes. Rønnestad et al. [33] compared the effects of 6 vs. 18 weekly sets per muscle group in young men. The participants performed a full-body routine following a linear periodization. Each training session consisted of leg press, leg extension, leg curl, seated chest press, seated rowing, latissimus pull-down, biceps curl, and shoulder press, performed in that order. Both RT volumes provided similar effects in trapezius muscle hypertrophy; however, the higher volume group achieved higher increases in thigh muscle hypertrophy in comparison with the lower volume group.

Bottaro et al. [34] compared the effects of 2 vs. 6 weekly sets per muscle group on upper and lower limb hypertrophy in young men. One group performed 3 sets of knee extensions and 1 set of elbow flexions, while the other performed 1 set of knee extensions and 3 sets of elbow flexion exercise. The sets were run until momentary muscle failure. Both RT volumes resulted in similar changes in biceps brachii and quadriceps muscle hypertrophy, with no difference between the groups. In the study by Mitchell et al. [35], young men performed unilateral knee extension at $80 \%$ of one-repetition maximum (1RM) until momentary muscle failure with 3 or 9 weekly sets per muscle group and obtained similar increases in thigh hypertrophy after 10 weeks of training. Cannon and Marino [36] compared RT volume with 3 or 9 weekly sets per muscle group in young and older women. The participants performed 10 repetitions of bilateral leg extension and leg curl at $75 \%$ of $1 \mathrm{RM}$. No difference was observed between the groups for knee extension muscle hypertrophy. In contrast to Bottaro et al. [34], Sooneste et al. [37] reported higher increases in elbow flexors muscle hypertrophy for 6 weekly sets per muscle group in comparison with 2 sets in young men. The participants trained unilateral biceps curl until momentary muscle failure or until completion of 10 repetitions. The training was supervised by a researcher.

Radaelli et al. [38] compared the impact of 4 vs. 12 weekly sets per muscle group on lower and upper body muscle hypertrophy in older women. Both groups performed bilateral knee extension, lat pull-down, bilateral leg press, dumbbell elbow flexion, bilateral leg curl, bench press, triceps extension, hip abduction and adduction, and abdominal crunch. After 20 weeks of training, both groups achieved significant increases for biceps brachii and vastus intermedius; however, the higher volume group obtained greater increases in vastus intermedius muscle thickness in comparison with the lower volume group. Using a similar study protocol, Radaelli et al. [39] compared 4 vs. 12 weekly sets per muscle group on lower body muscle hypertrophy in older women. The participants performed a fullbody routine with 15-20 maximum reps. However, this time, the groups achieved significant increases in thigh muscle hypertrophy after a 6 -week training period with no differences between groups.

A following study by Radaelli et al. [40] compared the effects of 6 vs. 18 vs. 30 weekly sets per muscle group on arm muscle hypertrophy in young men. The participants were not involved in RT, but were experienced in traditional military training that included calisthenic body-weight exercises. The training protocol involved bench press, leg press, lat pull down, leg extension, shoulder press, leg curl, biceps curl, abdominal crunch lying on the floor, and triceps extension. The subjects performed sets with 8-12 repetitions until momentary muscle failure under close supervision. Both 18- and 30-set groups achieved higher increases in elbow flexors hypertrophy in comparison with the 6-set group, with greater increases in the 30-set group than in the 18-set group. The highest volume group obtained higher increases in elbow extensors hypertrophy in comparison with the 6 - and 18-set groups, but no difference was reported between 6 and 18 sets.

Ribeiro et al. [41] found similar effects on lean body mass when comparing 3 vs. 9 weekly sets per muscle group in elderly women. The participants performed supervised full-body routine with 8 exercises done in the following order: chest press, horizontal leg press, seated row, knee extension, preacher curl, leg curl, triceps pushdown, and seated calf raise. The sets were 
Table 1. Summary of studies investigating the effects of resistance training volume on muscle hypertrophy and body composition in untrained subjects

\begin{tabular}{llcccc}
\hline Study & Year & $\begin{array}{c}\text { Length of } \\
\text { intervention }\end{array} \quad$ Participants & Training protocol & Supervised & $\begin{array}{c}\text { Hypertrophy } \\
\text { measurement }\end{array}$
\end{tabular}

No difference between volumes

\begin{tabular}{lccclcc}
\hline $\begin{array}{l}\text { Starkey } \\
\text { et al. [30] }\end{array}$ & 1996 & $3 \times /$ wk -14 wk & $\begin{array}{c}\text { Young } \\
\text { subjects }\end{array}$ & $\begin{array}{l}\text { Knee extension and } \\
\text { flexion with 8-12 reps } \\
\text { until muscle failure }\end{array}$ & N/R & Thigh MT-US \\
\hline
\end{tabular}

\begin{tabular}{|c|c|c|c|c|c|c|c|}
\hline $\begin{array}{l}\text { McBride } \\
\text { et al. [31] }\end{array}$ & 2003 & $2 \times / w k-12 w k$ & $\begin{array}{l}\text { Young } \\
\text { subjects }\end{array}$ & $\begin{array}{l}\text { Biceps curl and } \\
\text { leg press following } \\
\text { undulating } \\
\text { periodization }\end{array}$ & $\mathrm{N} / \mathrm{R}$ & $\begin{array}{l}\text { Total fat-free mass } \\
\text { DXA }\end{array}$ & $\begin{array}{l}\text { 1-SET }=6 \text {-SET } \\
\text { ( } 2 \text { vs. } 12 \text { weekly sets } \\
\text { per muscle group) }\end{array}$ \\
\hline $\begin{array}{l}\text { Galvão } \\
\text { and Taaffe } \\
{[32]}\end{array}$ & 2005 & $2 \times / w k-20 w k$ & $\begin{array}{l}\text { Elderly } \\
\text { subjects }\end{array}$ & $\begin{array}{l}\text { Full-body routine } \\
\text { performing } 8 \text { reps until } \\
\text { muscle failure }\end{array}$ & Yes (1:6) & $\begin{array}{l}\text { Total fat-free mass } \\
\text { DXA }\end{array}$ & $\begin{array}{l}\text { 1-SET }=3 \text {-SET } \\
\text { ( } 2 \text { vs. } 6 \text { weekly sets } \\
\text { per muscle group) }\end{array}$ \\
\hline
\end{tabular}

\begin{tabular}{|c|c|c|c|c|c|c|c|}
\hline $\begin{array}{l}\text { Mitchell } \\
\text { et al. [35] }\end{array}$ & 2012 & $3 \times / w k-10 w k$ & Young men & $\begin{array}{l}\text { Unilateral knee exten- } \\
\text { sion at } 80 \% \text { of } 1 \mathrm{RM} \\
\text { until muscle failure }\end{array}$ & $\mathrm{N} / \mathrm{R}$ & Thigh volume MRI & $\begin{array}{l}\text { 1-SET = 3-SET } \\
\text { (3 vs. } 9 \text { weekly sets } \\
\text { per muscle group) }\end{array}$ \\
\hline $\begin{array}{l}\text { Radaelli } \\
\text { et al. [38] }\end{array}$ & 2014 & $2 \times / w k-6 w k$ & $\begin{array}{l}\text { Elderly } \\
\text { women }\end{array}$ & $\begin{array}{l}\text { Full-body routine } \\
\text { performing } 15-20 \\
\text { maximum reps }\end{array}$ & Yes & $\begin{array}{l}\text { Knee extensors } \\
\text { MT-US }\end{array}$ & $\begin{array}{l}\text { 1-SET }=3 \text {-SET } \\
\text { (4 vs. } 12 \text { weekly sets } \\
\text { per muscle group) }\end{array}$ \\
\hline $\begin{array}{l}\text { Ribeiro } \\
\text { et al. [41] }\end{array}$ & 2015 & $3 \times / w k-12 w k$ & $\begin{array}{l}\text { Elderly } \\
\text { women }\end{array}$ & $\begin{array}{l}\text { Full-body routine } \\
\text { performing } 10-15 \\
\text { maximum reps }\end{array}$ & Yes $(1: 1)$ & $\begin{array}{l}\text { Total fat-free mass } \\
\text { DXA }\end{array}$ & $\begin{array}{l}\text { 1-SET = 3-SET UL } \\
\text { (3 vs. } 9 \text { weekly sets } \\
\text { per muscle group); } \\
\text { 1-SET = 3-SET LL } \\
\text { ( } 6 \text { vs. } 18 \text { weekly sets } \\
\text { per muscle group) }\end{array}$ \\
\hline
\end{tabular}

Favoured higher volume

\begin{tabular}{|c|c|c|c|c|c|c|c|}
\hline $\begin{array}{l}\text { Sooneste } \\
\text { et al. [37] }\end{array}$ & 2013 & $2 \times / w k-12 w k$ & Young men & $\begin{array}{l}\text { Biceps curl at } 80 \% \\
\text { of } 1 \mathrm{RM} \text { until muscle } \\
\text { failure or complete } \\
10 \text { repetitions }\end{array}$ & Yes & $\begin{array}{l}\text { Biceps brachii and } \\
\text { brachialis CSA-MRI }\end{array}$ & $\begin{array}{l}1-\mathrm{SET}<3-\mathrm{SET} \\
(2 \text { vs. } 6 \text { weekly sets } \\
\text { per muscle group) }\end{array}$ \\
\hline $\begin{array}{l}\text { Rønnestad } \\
\text { et al. [33] }\end{array}$ & 2007 & $3 \times / w k-11 w k$ & Young men & $\begin{array}{l}\text { Full-body routine } \\
\text { following linear } \\
\text { periodization }\end{array}$ & Partial & $\begin{array}{l}\text { Thigh and trapezius } \\
\text { MRI }\end{array}$ & $\begin{array}{l}\text { 1-SET }=3 \text {-SET UL } \\
\text { (6 vs. } 18 \text { weekly sets } \\
\text { per muscle group); } \\
\text { 1-SET < } 3 \text {-SET LL } \\
\text { (6 vs. } 18 \text { weekly sets } \\
\text { per muscle group) }\end{array}$ \\
\hline
\end{tabular}




\section{HUMAN MOVEMENT}

D. Souza, M. Barbalho, P. Gentil, Resistance training volume, muscle size, and lean body mass

\begin{tabular}{|c|c|c|c|c|c|c|}
\hline $\begin{array}{l}\text { Radaelli et } \\
\text { al. [39] }\end{array}$ & 2014 & $2 \times / w k-20 w k$ & Elderly women & $\begin{array}{l}\text { Full-body routine } \\
\text { following linear } \\
\text { periodization } \\
\text { performing maximum } \\
\text { repetitions }\end{array}$ & Yes & $\begin{array}{l}\text { Vastus intermedius } \\
\text { and biceps brachii } \\
\text { MT-US }\end{array}$ \\
\hline
\end{tabular}

Radaelli et $2015 \quad 3 \times /$ wk -6 mo Young men
al. [40]
Full-body routine performing 8-12 repetitions until muscle failure

$\begin{array}{ll}\text { Yes } & \begin{array}{l}\text { Elbow flexor and } \\ \text { elbow extensor }\end{array} \\ \text { MT-US }\end{array}$
elbow extensor MT-US
1-SET $=3$-SET UL

(4 vs. 12 weekly sets per muscle group); 1-SET < 3-SET LL (4 vs. 12 weekly sets per muscle group)

1-SET $<3-S E T<$

5 -SET elbow flexor (6 vs. 18 vs. 30 weekly sets per muscle group); 1-SET $=3$-SET $<5$-SET elbow extensor (6 vs. 18 vs. 30 weekly sets per muscle group)

1-SET < 3-SET (6 vs. 18 weekly sets per muscle group)

Correa et $20153 \times /$ wk - 11 wk Postmenopausal Full-body routine

al. [42] women performing 15

maximum reps

$\begin{array}{ll}\text { N/R } & \text { Knee extensors } \\ & \text { MT-US }\end{array}$

1RM - one-repetition maximum, BIA - bioelectrical impedance, CSA-MRI - cross-sectional area by magnetic resonance imaging, DXA - dual energy X-ray absorptiometry, HIT - high intensity training, LL - lower limb, MMF - momentary muscle failure, MRI - magnetic resonance imaging, MT-US - muscle thickness by ultrasound, N/R - not reported, UL - upper limb, $=-$ no significant difference between groups, $<-$ significantly smaller than

performed with $10-15$ repetitions maximum. Correa et al. [42] reported higher increases in knee extensor muscle hypertrophy for 18 weekly sets per muscle group in comparison with 6 sets in postmenopausal women. The participants performed full-body routine involving bench press, biceps curl, dumbbell triceps extensions, one arm row back, leg press, knee extensor, and knee flexion and abdomen crunch. The sets were carried out until 15 repetitions maximum.

Giessing et al. [43] recruited recreational sports participants of both sexes to investigate two RT protocols: high intensity training performing 1 set per exercise until momentary muscle failure plus drop-set vs. 3 sets per exercise involving non-repetition maximum; the total was 9 vs. 27 weekly sets per muscle group. The participants performed supervised fullbody circuit-based routine with 8 exercises done in the following order: chest press, heel raise, rear deltoid, elbow flexion, seated row, knee extension, knee flexion, abdominal flexion, push-ups. The results for lean body mass showed no difference between groups after 10 weeks.

Therefore, of the 14 studies involving untrained participants, 5 reported that an increase in training volume provided greater results in at least one measure [33, 37, 39, 40, 42]. Among the studies that revealed better results for the high-volume condition, the upper limit achieved was 30 weekly sets per muscle group [40]. Four studies did not inform about training supervision [30, 31, 35, 42] and 1 did not relate randomization [31]. Regarding the set endpoints definition,
Starkey et al. [30] reported that the participants performed sets until volitional fatigue, which suggests that they performed sets at self-determined repetition maximum. In addition, the values of RPE indicate that the intensity of effort was increased during the study and near-maximum efforts were achieved at the end. While 1 study performed sets at non-repetition maximum [36], 6 involved sets at repetition maximum [31, 33, $38,39,41,42]$ and 5 applied sets at muscle failure $[30,34,35,40,43]$ in accordance with the previous definition [24]. Considering that in the study by Sooneste et al. [37], the participants performed sets until momentary failure or until achieving 10 repetitions, is not clear if both groups were able to obtain similar intensity of effort during sets since is not defined how much effort represented 10 repetitions to the participants.

Regarding hypertrophy and body composition measures, 6 studies assessed muscle thickness by ultrasound [30, 34, 38-40, 42], 4 evaluated muscle crosssectional area by magnetic resonance imaging [33, 35-37], 3 established lean body mass by dual energy X-ray absorptiometry [31, 32, 41] and 1 by bioimpedance [43].

\section{Trained subjects}

Eight studies involving resistance-trained participants were included in this review (Table 2). Ostrowski et al. [44] investigated the effects of 3 vs. 6 vs. 12 weekly sets per muscle group in experienced resist- 
Table 2. Summary of studies investigating the effects of resistance training volume on muscle hypertrophy and body composition in trained subjects

\begin{tabular}{|c|c|c|c|c|c|c|c|}
\hline Study & Year & $\begin{array}{l}\text { Length of } \\
\text { intervention }\end{array}$ & Participants & Training protocol & Supervised & $\begin{array}{l}\text { Hypertrophy } \\
\text { measurement }\end{array}$ & Outcomes \\
\hline \multicolumn{8}{|c|}{ No difference between volumes } \\
\hline $\begin{array}{l}\text { Rhea et al. } \\
\text { [46] }\end{array}$ & 2002 & $3 \times / w k-12 w k$ & $\begin{array}{l}\text { Young } \\
\text { men }\end{array}$ & $\begin{array}{l}\text { Bench and leg press } \\
\text { following undulating } \\
\text { periodization perform- } \\
\text { ing sets until muscle } \\
\text { failure }\end{array}$ & $\mathrm{N} / \mathrm{R}$ & $\begin{array}{l}\text { Total fat-free mass } \\
\text { plethysmography } \\
\text { and circumference }\end{array}$ & $\begin{array}{l}\text { 1-SET }=3 \text {-SET } \\
\text { ( } 3 \text { vs. } 9 \text { weekly sets } \\
\text { per muscle group) }\end{array}$ \\
\hline $\begin{array}{l}\text { Hackett et al. } \\
\text { [48] }\end{array}$ & 2018 & $3 \times /$ wk -12 wk & $\begin{array}{l}\text { Young } \\
\text { men }\end{array}$ & $\begin{array}{l}\text { Split routine } \\
\text { performing } \\
10 \text { maximum reps }\end{array}$ & Yes & $\begin{array}{l}\text { Total fat-free mass } \\
\text { DXA }\end{array}$ & $\begin{array}{l}5 \text {-SET = 10-SET UL } \\
\text { (9 vs. } 14 \text { weekly sets } \\
\text { per muscle group); } \\
5 \text {-SET = } 10 \text {-SET LL } \\
\text { (14 vs. } 24 \text { weekly sets } \\
\text { per muscle group) }\end{array}$ \\
\hline $\begin{array}{l}\text { Heaselgrave } \\
\text { et al. [51] }\end{array}$ & 2019 & $1-2 \times / w k-6 w k$ & $\begin{array}{l}\text { Young } \\
\text { men }\end{array}$ & $\begin{array}{l}\text { Biceps-based RT } \\
\text { performing } 10-12 \text { reps } \\
\text { using the repetitions } \\
\text { in reserve }\end{array}$ & Yes & $\begin{array}{l}\text { Biceps brachii } \\
\text { MT-US }\end{array}$ & $\begin{array}{l}9 \text {-SET }=18-S E T= \\
27-S E T \text { ( } 9 \text { vs. } 18 \text { vs. } \\
27 \text { weekly sets per } \\
\text { muscle group) }\end{array}$ \\
\hline
\end{tabular}

Favoured higher volume

\begin{tabular}{lcccl}
\hline $\begin{array}{l}\text { Schoenfeld } \\
\text { et al. [49] }\end{array}$ & 2019 & $3 \times / \mathrm{wk}-8 \mathrm{wk}$ & $\begin{array}{c}\text { Young } \\
\text { men }\end{array}$ & $\begin{array}{l}\text { Full-body routine } \\
\text { performing } 8-12 \text { reps } \\
\text { until muscle failure }\end{array}$
\end{tabular}

Yes

Elbow flexors, elbow 1-SET < 5-SET elbow extensors, mid thigh, flexors; 1 -SET $=3$-SET = lateral thigh MT-US 5-SET elbow extensors (6 vs. 18 vs. 30 weekly sets per muscle group); 1-SET $<$ 5-SET mid thigh; 1 -SET $<5$-SET lateral thigh ( 9 vs. 21 vs. 45 weekly sets per muscle group)

\begin{tabular}{llll}
\hline Favoured lower volume & & \\
\hline Barbalho et al. $2019 \quad 3 \times / \mathrm{wk}-24 \mathrm{wk}$ & Young & $\begin{array}{l}\text { Split routine } \\
\text { [50] }\end{array}$ \\
& women & $\begin{array}{l}\text { following undulating } \\
\text { periodization }\end{array}$ \\
& & $\begin{array}{l}\text { performing sets until } \\
\text { muscle failure }\end{array}$
\end{tabular}

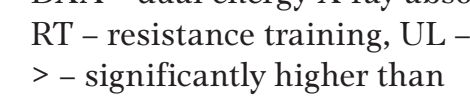


D. Souza, M. Barbalho, P. Gentil, Resistance training volume, muscle size, and lean body mass

ance-trained men. The RT program was supervised and involved split routine with 6 exercises per session following a periodized program with sets performed until momentary muscle failure. All 3 RT volumes resulted in significant increases in thigh and triceps brachii muscle hypertrophy, with no differences between the groups. Hass et al. [45] compared 6 vs. 18 weekly sets per muscle group in recreational weightlifters. The training protocol consisted in a circuit involving 9 exercises. The sets were performed until volitional fatigue and there was no difference for lean body mass between the groups. However, it is important to point out that 7 participants in the higher volume group did complete the study, among whom 5 did not adhere to the training protocol and 2 experienced tendon inflammation in shoulder and knee joints. Rhea et al. [46] found no difference in muscle hypertrophy between groups of young men who performed 3 vs. 9 weekly sets per muscle group of bench press and leg press following an undulating periodization. Both groups performed 8-12 repetitions of biceps curl, lat pull-down, abdominal crunches, back extensions, and seated rows.

Amirthalingam et al. [47] investigated the effects of 5 vs. 10 sets per exercise of RT volume on arm and thigh muscle hypertrophy. The 10 or 5 sets were implemented in the first 2 multi-joint exercises of each training session, resulting in approximately 14 and 24 weekly sets per muscle group. The participants were asked to perform repetitions until momentary muscle failure in the last set of each exercise. There was no difference between groups in arm and thigh muscle thickness; however, the 5-set group obtained significant increases in trunk and arms lean body mass. Subsequently, the same researchers used a similar study design during 12 weeks, evaluating body composition in young men [48]. The results revealed no difference between groups in lower and upper limb lean body mass.

Schoenfeld et al. [49] investigated the effects of 6 vs. 18 vs. 30 sets for upper body and 9 vs. 21 vs. 45 weekly sets for lower body muscles in young men. The participants performed a full-body routine involving 7 exercises per session 3 times per week during 8 weeks. The sets consisted of 8-12 repetitions until momentary muscle failure. The group that applied the 5-set RT volume per exercise achieved higher increases in elbow flexors, mid and lateral thigh muscle hypertrophy than the 1-set group, but no significant difference was observed between the 1- and 3-set groups. All groups obtained significant increases in elbow extensors muscle thickness, with no significant difference between groups.
Barbalho et al. [50] investigated the effect of 5, 10, 15 , and 20 weekly sets per muscle group in arm, pectoralis major, quadriceps, and gluteus muscle hypertrophy in resistance-trained women. The participants performed a split routine with 3 different programs, and sets were performed until momentary muscle failure. The training sessions were implemented 3 times per week during 24 weeks, under supervision. All groups achieved significant gains in muscle size for all sites evaluated. However, the 5- and 10-set groups obtained greater gains in comparison with the 15- and 20-set groups for biceps brachii, triceps brachii, pectoralis major, quadriceps femoris, and gluteus maximum. In addition, the 15-set group achieved grater increases in comparison with the 20-set group for triceps brachii, pectoralis major, and gluteus maximum.

Heaselgrave et al. [51] compared the effects of 9 vs. 18 vs. 27 weekly sets per muscle group on biceps brachii muscle hypertrophy. The participants performed a biceps-based RT during 6 weeks. The training protocol included seated supine biceps curl, supine grip bent-over row, and supine grip pulldown. The 9-set group trained only once per week with 3 sets per exercise, while the 18-set group trained twice per week using the same routine. The 27-set group performed 4-5 sets per exercise and trained twice per week. The subjects implemented 10-12 repetitions per set and monitored exercise intensity by using the RPE scale. All groups achieved significant gains in biceps muscle size, with no difference between groups.

Therefore, of the 8 studies involving resistancetrained subjects, 1 reported that an increase in training volume provided greater increases in muscle hypertrophy [49], with the upper limit achieved of 45 weekly sets per muscle group. One study revealed better results for lower volume [50], with the lower threshold of 5 sets per week. Only one study did not inform about training supervision [46]. With regard to the set end points, in the study by Hass et al. [45], the participants performed self-selected repetition maximum; the RPE results suggest that both groups progressed the effort similarly. Six studies applied sets until muscle failure [44-46, 49-51] and 2 studies performed repetitions maximum [47, 48].

Regarding muscle hypertrophy and body composition measures, 6 studies assessed muscle thickness by ultrasound [39, 44, 49-51], while others evaluated lean body mass by skin folds [45], dual energy X-ray absorptiometry [48], and plethysmography [46]. 


\section{Discussion}

The present study aimed to critically review the relevant studies investigating the effects of RT volume on muscle hypertrophy and lean body mass. We observed a high heterogeneity between the training protocols, population characteristics, length of intervention, supervision status, measures of body composition and muscle hypertrophy. In addition, some studies did not report research procedures properly, as supervision status or randomization. This, summed with the complexity involved in RT prescription, makes it difficult to isolate a single research variable.

Interestingly, the divergence about training volume and muscle hypertrophy seems to be more present in untrained than in trained participants, where only 1 study reported superior findings for performing higher volumes. This seems to challenge the common belief that it is necessary to increase volume over time. In this sense, it is important to note that previous studies revealed gains in muscle size after reductions in training volume in people with months or even years of RT experience [44, 52], and others reported that increasing from 1 to 3 sets per exercise did not bring benefits in terms of body composition in subjects with many years of training [45]. The different results in trained and untrained individuals might be influenced by varied perceptions of maximum efforts, since previous studies implied that less experienced subjects had more difficulty in predicting momentary muscle failure [53]. Considering that increased volume might serve as a strategy to increase effort [22], an increase in training volume might be beneficial to overcome the adaptation threshold in such cases, as illustrated in Figure 1.

The intensity of effort may explain the divergent results observed in some studies, such as Bottaro et al.
[34] and Sooneste et al. [37]. The former study found no difference between the effect of volume conditions on arm muscle hypertrophy, while the latter showed benefits for the higher volume group. One should note that both studies implemented similar supervised training protocols and used similar volumes ( 3 vs. 9 weekly sets per muscle group). However, whereas in the Bottaro et al. [34] study, the participants performed sets until momentary muscle failure, those in the Sooneste et al. [37] study performed sets until momentary muscle failure or until complete 10 repetitions. In addition, in the Sooneste et al. [37] study, the supervisor did not provide any verbal encouragement or spot, which might prevent the subjects from performing maximum efforts during the sets [54].

Although the performance of sets until momentary muscle failure is not essential to induce muscle hypertrophy, it seems that when training with maximum effort, the adaptive threshold might be reached with fewer sets [25], which is in agreement with the suggestion that optimal volume decreases with increased training intensity [18]. This may explain the similar results in thigh muscle hypertrophy observed in previous studies comparing 3 vs. 9 weekly sets per muscle group in untrained subjects training at high intensity of effort [30, 35, 36]. In this sense, performing maximum efforts might stimulate muscle hypertrophy in a time-efficient strategy, as illustrated in Figure 1.

Conflicting results were observed for muscle hypertrophy response in different body regions. Whilst some studies have shown that upper and lower body respond similarly to low and high volume [34, 50], other studies have found dissimilar results between upper and lower body [33, 38], with lower body responding better to higher volumes. Indeed, performing maximum

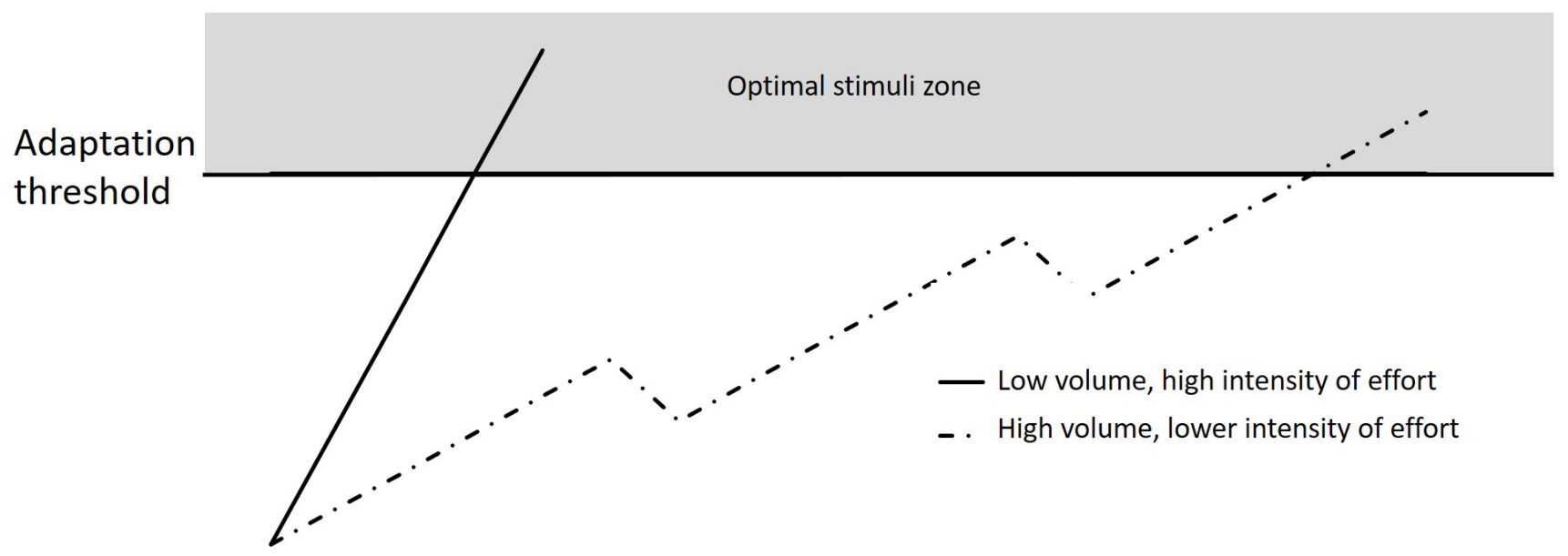

Figure 1. Illustration representing the threshold model 
D. Souza, M. Barbalho, P. Gentil, Resistance training volume, muscle size, and lean body mass

effort in lower limb RT exercises might be more difficult to achieve in comparison with the upper limb [53, 54]. Again, the increased volume might be an alternative to progressively increasing effort in this case.

A previous meta-analysis was not able to provide information about volumes higher than 10 weekly sets per muscle group [11]; however, recent studies helped to fill that gap. Schoenfeld et al. [49] found greater increases for the higher volume group in biceps brachii and thigh muscle hypertrophy. Although these findings reinforce the role of volume in muscle hypertrophy, the results do not seem to follow a dose-dependent response, since 30 sets were significantly greater than 6 sets but the results for the 18-set group were not significantly different from those in the 6- and 30-set groups. Moreover, it is difficult to recognize whether these results could be maintained in long-term observation since the study lasted 8 weeks. In contrast to these findings, another study found no benefits of going over 10 sets per week; in fact, there was a trend for decreasing results when exceeding this number [50].

Therefore, challenging the 'volume-based theory,' recent studies investigating the effects of RT volume on muscle hypertrophy and lean body mass in resistance-trained subjects have suggested that a plateau exists when RT is performed with high intensity of effort (i.e. until momentary muscle failure) and further increases in the number of sets provide no benefit and even can promote a reduction in the results $[47,48$, $50,51]$. This is in agreement with a previous suggestion by Wernbom et al. [18] that there is a plateau in muscle hypertrophy after a certain volume has been reached and there might be even a decline when the volume is extended beyond that point. These findings corroborate an early study by Ostrowski et al. [44] that reported similar muscle hypertrophy between groups performing 3, 6, and 12 weekly sets per muscle group. However, the higher volume (12-set) group presented a trend of the testosterone/cortisol ratio decrease, suggesting an early overtraining state. Together, these findings indicate that instead of a linear dose-response relationship between training volume and muscle hypertrophy and lean body mass, the dose-response RT might follow an inverted U-shape, with around 5-10 sets per week constituting an upper threshold for optimal adaptation when training at higher efforts. In this regard, the control of training volume seems to be particularly important over a long term since only 1 study involved periods longer than 12 weeks and showed that performing higher training volumes resulted in a trend to bring less increases in muscle size over 24 weeks of training [50].
Another relevant aspect to consider in RT adaptations is the supervision ratio; previous studies involving untrained and trained men found greater improvements in muscle adaptations when the training had a closer supervision $[54,55]$. Furthermore, Steele et al. [56] showed significant improvements in body composition after low-volume RT involving higher efforts under close supervision in older people. However, the negative changes in body composition were similar when participants interrupted training or trained at higher volume and lower efforts without supervision. In this context, it is possible to suggest that high volume could be beneficial when supervision is low or partial, as observed in the study by Rønnestad et al. [33]. Supervision seems to be especially important in studies involving older people since this population presents more difficulty in achieving higher efforts in comparison with young people [57]. Considering that the closer supervision must be critical to optimal results, the absence of adequately reported supervision rate might be an important limitation in some studies included in our analysis.

In practical terms, the effects of RT volume on muscle hypertrophy might be explained by the threshold theory. In this sense, performing sets with higher efforts could be used to overcome this threshold in a time-efficient manner among both beginners and trained practitioners [25, 43]. Notwithstanding, it is possible that an increase in RT volume could be beneficial when training with low effort, as shown in Figure 1. According to the analysed studies, a threshold seems to be reached with 5-10 weekly sets per muscle group when training until momentary muscle failure [50].

\section{Conclusions}

In conclusion, our findings suggest that both high and low volume RT have a significant effect on muscle hypertrophy and that RT volume might not be the main variable to affect muscle hypertrophy or lean body mass. The generalization of the 'volume-based theory' as an 'infinity and beyond' approach might be detrimental to optimal muscle hypertrophy, especially when one tries to apply high volume and high intensity of effort concomitantly. Thus, we suggest that volume should be controlled, and other variables should be manipulated in order to bring optimal and sustainable results.

\section{Acknowledgements}

This research did not receive any specific grant from funding agencies in the public, commercial, or not-forprofit sectors. 


\section{Disclosure statement}

No author has any financial interest or received any financial benefit from this research.

\section{Conflict of interest}

The authors state no conflict of interest.

\section{References}

1. Srikanthan P, Karlamangla AS. Muscle mass index as a predictor of longevity in older adults. Am J Med. 2014; 127(6):547-553; doi: 10.1016/j.amjmed.2014.02.007.

2. Thibault R, Makhlouf A-M, Mulliez A, Gonzalez MC, Kekstas G, Kozjek NR, et al. Fat-free mass at admission predicts 28-day mortality in intensive care unit patients: the international prospective observational study Phase Angle Project. Intensive Care Med. 2016;42(9):14451453; doi: 10.1007/s00134-016-4468-3.

3. Janssen I, Heymsfield SB, Ross R. Low relative skeletal muscle mass (sarcopenia) in older persons is associated with functional impairment and physical disability. J Am Geriatr Soc. 2002;50(5):889-896; doi: 10.1046/j.1532-5415.2002.50216.x.

4. Steele J, Fisher J, Skivington M, Dunn C, Arnold J, Tew G, et al. A higher effort-based paradigm in physical activity and exercise for public health: making the case for a greater emphasis on resistance training. BMC Public Health. 2017;17:300; doi: 10.1186/s12889-0174209-8.

5. Steffl M, Bohannon RW, Sontakova L, Tufano JJ, Shiells K, Holmerova I. Relationship between sarcopenia and physical activity in older people: a systematic review and meta-analysis. Clin Interv Aging. 2017;12:835-845; doi: 10.2147/CIA.S132940.

6. Paoli A, Bianco A. What is fitness training? Definitions and implications: a systematic review article. Iran J Public Health. 2015;44(5):602-614.

7. Phillips SM. A brief review of critical processes in exercise-induced muscular hypertrophy. Sports Med. 2014; 44(Suppl. 1):S71-S77; doi: 10.1007/s40279-014-0152-3.

8. Fisher J, Steele J, Smith D. Evidence-based resistance training recommendations for muscular hypertrophy. Med Sport. 2013;17(4):217-235; doi: 10.5604/17342 260.1081302.

9. Gentil P, Arruda A, Souza D, Giessing J, Paoli A, Fisher J, et al. Is there any practical application of meta-analytical results in strength training? Front Physiol. 2017;8:1; doi: 10.3389/fphys.2017.00001.

10. Schoenfeld BJ. The mechanisms of muscle hypertrophy and their application to resistance training. J Strength Cond Res. 2010;24(10):2857-2872; doi: 10.1519/JSC. 0b013e3181e840f3.

11. Schoenfeld JB, Ogborn D, Krieger JW. Dose-response relationship between weekly resistance training volume and increases in muscle mass: a systematic review and meta-analysis. J Sports Sci. 2017;35(11):1073-1082; doi: 10.1080/02640414.2016.1210197.
12. Krieger JW. Single vs. multiple sets of resistance exercise for muscle hypertrophy: a meta-analysis. J Strength Cond Res. 2010;24(4):1150-1159; doi: 10.1519/JSC. 0b013e3181d4d436.

13. Arruda A, Souza D, Steele J, Fisher J, Giessing J, Gentil P. Reliability of meta-analyses to evaluate resistance training programmes. J Sports Sci. 2017;35(20):19821984; doi: 10.1080/02640414.2016.1243799.

14. Carpinelli RN. Critical review of a meta-analysis for the effect of single and multiple sets of resistance training on strength gains. Med Sport. 2012;16(3):122-130; doi: 10.5604/17342260.1011393.

15. Winett RA, Carpinelli RN. Examining the validity of exercise guidelines for the prevention of morbidity and all-cause mortality. Ann Behav Med. 2000;22(3):237245; doi: 10.1007/BF02895119.

16. Burd NA, Mitchell CJ, Churchward-Venne TA, Phillips SM. Bigger weights may not beget bigger muscles: evidence from acute muscle protein synthetic responses after resistance exercise. Appl Physiol Nutr Metab. 2012;37(3):551-554; doi: 10.1139/h2012-022.

17. Winett RA, Wojcik JR, Fox LD, Herbert WG, Blevins JS, Carpinelli RN. Effects of low volume resistance and cardiovascular training on strength and aerobic capacity in unfit men and women: a demonstration of a threshold model. J Behav Med. 2003;26(3):183-195; doi: 10.1023/A:1023410302898.

18. Wernbom M, Augustsson J, Thomeé R. The influence of frequency, intensity, volume and mode of strength training on whole muscle cross-sectional area in humans. Sports Med. 2007;37(3):225-264; doi: 10.2165/ 00007256-200737030-00004.

19. Schoenfeld BJ. Is there a minimum intensity threshold for resistance training-induced hypertrophic adaptations? Sports Med. 2013;43(12):1279-1288; doi: 10.1007/s40279-013-0088-z.

20. Ogasawara R, Arihara Y, Takegaki J, Nakazato K, Ishii N. Relationship between exercise volume and muscle protein synthesis in a rat model of resistance exercise. J Appl Physiol. 2017;123(4):710-716; doi: 10.1152/japplphysiol.01009.2016.

21. Morton RW, Colenso-Semple L, Phillips SM. Training for strength and hypertrophy: an evidence-based approach. Curr Opin Physiol. 2019;10:90-95; doi: 10.1016/ j.cophys.2019.04.006.

22. Souza DC, Viana RB, Coswig VS, Fisher JP, Steele J, Gentil P. Comment on: volume for muscle hypertrophy and health outcomes: the most effective variable in resistance training. Sports Med. 2018;48(5):1281-1284; doi: 10.1007/s40279-018-0865-9.

23. Steele J. Intensity; in-ten-si-ty; noun. 1. Often used ambiguously within resistance training. 2 . Is it time to drop the term altogether? Br J Sports Med. 2014;48(22): 1586-1588; doi: 10.1136/bjsports-2012-092127.

24. Steele J, Fisher J, Giessing J, Gentil P. Clarity in reporting terminology and definitions of set endpoints in resistance training. Muscle Nerve. 2017;56(3):368-374; doi: 10.1002/mus.25557. 
D. Souza, M. Barbalho, P. Gentil, Resistance training volume, muscle size, and lean body mass

25. Fisher JP, Blossom D, Steele J. A comparison of volumeequated knee extensions to failure, or not to failure, upon rating of perceived exertion and strength adaptations. Appl Physiol Nutr Metab. 2016;41(2):168-174; doi: 10.1139/apnm-2015-0421.

26. Martorelli S, Cadore EL, Izquierdo M, Celes R, Martorelli A, Cleto VA, et al. Strength training with repetitions to failure does not provide additional strength and muscle hypertrophy gains in young women. Eur J Transl Myol. 2017;27(2):113-120; doi: 10.4081/ejtm. 2017.6339.

27. Teodoro JL, da Silva LXN, Fritsch CG, Baroni BM, Grazioli R, Boeno FP, et al. Concurrent training performed with and without repetitions to failure in older men: a randomized clinical trial. Scand J Med Sci Sports. 2019;29(8):1141-1152; doi: 10.1111/sms.13451.

28. Giessing J, Fisher J, Steele J, Rothe F, Raubold K, Eichmann B. The effects of low-volume resistance training with and without advanced techniques in trained subjects. J Sports Med Phys Fitness. 2016;56(3):249-258.

29. Paoli A, Moro T, Bianco A. Lift weights to fight overweight. Clin Physiol Funct Imaging. 2015;35(1):1-6; doi: 10.1111/cpf.12136.

30. Starkey DB, Pollock ML, Ishida Y, Welsch MA, Brechue WF, Graves JE, et al. Effect of resistance training volume on strength and muscle thickness. Med Sci Sports Exerc. 1996;28(10):1311-1320; doi: 10.1097/000057 68-199610000-00016.

31. McBride JM, Blaak JB, Triplett-McBride T. Effect of resistance exercise volume and complexity on EMG, strength, and regional body composition. Eur J Appl Physiol. 2003;90(5-6):626-632; doi: 10.1007/s00421003-0930-3.

32. Galvão DA, Taaffe DR. Resistance exercise dosage in older adults: single- versus multiset effects on physical performance and body composition. J Am Geriatr Soc. 2005;53(12):2090-2097; doi: 10.1111/j.1532-5415. 2005.00494.x.

33. Rønnestad BR, Egeland W, Kvamme NH, Refsnes PE, Kadi F, Raastad T. Dissimilar effects of one- and threeset strength training on strength and muscle mass gains in upper and lower body in untrained subjects. J Strength Cond Res. 2007;21(1):157-163; doi: 10.1519/001242 78-200702000-00028.

34. Bottaro M, Veloso J, Wagner D, Gentil P. Resistance training for strength and muscle thickness: effect of number of sets and muscle group trained. Sci Sport. 2011;26(5):259-264;doi:10.1016/j.scispo.2010.09.009.

35. Mitchell CJ, Churchward-Venne TA, West DWD, Burd NA, Breen L, Baker SK, et al. Resistance exercise load does not determine training-mediated hypertrophic gains in young men. J Appl Physiol. 2012;113(1):71-77; doi: 10.1152/japplphysiol.00307.2012.

36. Cannon J, Marino FE. Early-phase neuromuscular adaptations to high- and low-volume resistance training in untrained young and older women. J Sports Sci. 2010; 28(14):1505-1514;doi:10.1080/02640414.2010.517544.
37. Sooneste H, Tanimoto M, Kakigi R, Saga N, Katamoto S. Effects of training volume on strength and hypertrophy in young men. J Strength Cond Res. 2013;27(1):8-13; doi: 10.1519/JSC.0b013e3182679215.

38. Radaelli R, Botton CE, Wilhelm EN, Bottaro M, Brown LE, Lacerda F, et al. Time course of low- and high-volume strength training on neuromuscular adaptations and muscle quality in older women. Age. 2014;36(2): 881-892; doi: 10.1007/s11357-013-9611-2.

39. Radaelli R, Wilhelm EN, Botton CE, Rech A, Bottaro M, Brown LE, et al. Effects of single vs. multiple-set shortterm strength training in elderly women. Age. 2014;36(6): 9720; doi: 10.1007/s11357-014-9720-6.

40. Radaelli R, Fleck SJ, Leite T, Leite RD, Pinto RS, Fernandes L, et al. Dose-response of 1, 3, and 5 sets of resistance exercise on strength, local muscular endurance, and hypertrophy. J Strength Cond Res. 2015;29(5): 1349-1358; doi: 10.1519/JSC.0000000000000758.

41. Ribeiro AS, Schoenfeld BJ, Pina FLC, Souza MF, Nascimento MA, dos Santos L, et al. Resistance training in older women: comparison of single vs. multiple sets on muscle strength and body composition. Isokinet Exerc Sci. 2015;23(1):53-60; doi: 10.3233/IES-140564.

42. Correa CS, Teixeira BC, Cobos RCR, Macedo RCO, Kruger RL, Carteri RBK, et al. High-volume resistance training reduces postprandial lipaemia in postmenopausal women. J Sports Sci. 2015;33(18):1890-1901; doi: 10.1080/02640414.2015.1017732.

43. Giessing J, Eichmann B, Steele J, Fisher J. A comparison of low volume 'high-intensity-training' and high volume traditional resistance training methods on muscular performance, body composition, and subjective assessments of training. Biol Sport. 2016;33(3):241-249; doi: $10.5604 / 20831862.1201813$.

44. Ostrowski KJ, Wilson GJ, Weatherby R, Murphy PW, Lyttle AD. The effect of weight training volume on hormonal output and muscular size and function. J Strength Cond Res. 1997;11(1):148-154; doi: 10.1519/15334287(1997)011<0148:TEOWTV>2.3.CO;2.

45. Hass CJ, Garzarella L, de Hoyos D, Pollock ML. Single versus multiple sets in long-term recreational weightlifters. Med Sci Sports Exerc. 2000;32(1):235-242; doi: 10.1097/00005768-200001000-00035.

46. Rhea MR, Alvar BA, Ball SD, Burkett LN. Three sets of weight training superior to 1 set with equal intensity for eliciting strength. J Strength Cond Res. 2002;16(4): 525-529; doi: 10.1519/1533-4287(2002)016<0525:TS OWTS>2.0.CO;2.

47. Amirthalingam T, Mavros Y, Wilson GC, Clarke JL, Mitchell L, Hackett DA. Effects of a modified German volume training program on muscular hypertrophy and strength. J Strength Cond Res. 2017;31(11):3109-3119; doi: 10.1519/JSC.0000000000001747.

48. Hackett DA, Amirthalingam T, Mitchell L, Mavros Y, Wilson GC, Halaki M. Effects of a 12-week modified German volume training program on muscle strength and hypertrophy - a pilot study. Sports. 2018;6(1):7; doi: $10.3390 /$ sports 6010007 . 
49. Schoenfeld BJ, Contreras B, Krieger J, Grgic J, Delcastillo K, Belliard R, et al. Resistance training volume enhances muscle hypertrophy but not strength in trained men. Med Sci Sports Exerc. 2019;51(1):94-103; doi: 10.1249/MSS.0000000000001764.

50. Barbalho M, Coswig VS, Steele J, Fisher JP, Paoli A, Gentil P. Evidence for an upper threshold for resistance training volume in trained women. Med Sci Sports Exerc. 2019;51(3):515-522; doi: 10.1249/MSS.00000 00000001818.

51. Heaselgrave SR, Blacker J, Smeuninx B, McKendry J, Breen L. Dose-response relationship of weekly resistance-training volume and frequency on muscular adaptations in trained men. Int J Sports Physiol Perform. 2019;14(3):360-368; doi: 10.1123/ijspp.2018-0427.

52. Bickel CS, Cross JM, Bamman MM. Exercise dosing to retain resistance training adaptations in young and older adults. Med Sci Sports Exerc. 2011;43(7):11771187; doi: 10.1249/MSS.0b013e318207c15d.

53. Steele J, Endres A, Fisher J, Gentil P, Giessing J. Ability to predict repetitions to momentary failure is not perfectly accurate, though improves with resistance training experience. PeerJ. 2017;5:e4105; doi: 10.7717/ peerj.4105.

54. Gentil P, Bottaro M. Influence of supervision ratio on muscle adaptations to resistance training in nontrained subjects. J Strength Cond Res. 2010;24(3):639-643; doi: 10.1519/JSC.0b013e3181ad3373.

55. Mazzetti SA, Kraemer WJ, Volek JS, Duncan ND, Ratamess NA, Gómez AL, et al. The influence of direct supervision of resistance training on strength performance. Med Sci Sports Exerc. 2000;32(6):1175-1184; doi: 10.1097/00005768-200006000-00023.

56. Steele J, Raubold K, Kemmler W, Fisher J, Gentil P, Giessing J. The effects of 6 months of progressive high effort resistance training methods upon strength, body composition, function, and wellbeing of elderly adults. BiomedRes Int. 2017;2017:2541090; doi: 10.1155/2017/ 2541090.

57. Pruitt LA, Taaffe DR, Marcus R. Effects of a one-year high-intensity versus low-intensity resistance training program on bone mineral density in older women. J Bone Miner Res. 1995;10(11):1788-1795; doi: 10.1002/jbmr. 5650101123. 